\title{
Intraoperative pleural lavage cytology: More evidence on its prognostic and staging values
}

\author{
Diego Gonzalez-Rivas, $\mathrm{MD},{ }^{\mathrm{a}}$ and Ramón Rami-Porta, $\mathrm{MD}^{\mathrm{b}}$
}

See related article on pages 2659-64.

Since the introduction of the tumor, node, and metastasis (TNM) classification of malignant tumors in 1943, there have been periodic revisions updating the classifications of the different tumors. The most recent revision for lung cancer appeared in the seventh edition of the TNM classification of malignant tumors, published by the Union for International Cancer Control, the American Joint Committee on Cancer, and the International Association for the Study of Lung Cancer. ${ }^{1-3}$ Among other innovations, pleural dissemination (malignant pleural effusion and malignant pleural nodules) was upstaged from the previous T4 category to the new M1a category. However, cancer cells can be present in the pleural cavity with no pleural effusion. This finding can be the result of exfoliation from lung cancer or surgical manipulation in operated patients, but its significance is not clear. Pleural lavage cytology (PLC) provides a cytologic diagnosis at the time of surgery, but the result of PLC is not included as a descriptor in the seventh edition of the TNM classification and staging system.

Some studies suggest that a positive PLC is an independent prognostic factor and a predictor of tumor recurrence, ${ }^{4}$ but others do not support the value of pleural lavage. ${ }^{5}$ The International Pleural Lavage Cytology Collaborators recommended that a single increase in the $\mathrm{T}$ category up to a maximum of $\mathrm{T} 4$ be assigned to patients with positive PLC results. $^{6}$

In the original paper published in this issue, Kameyama and colleagues ${ }^{7}$ studied a retrospective series of 11,073 patients operated on for non-small cell lung cancer in 2004 and followed up for more than 5 years. Of these, 4171 underwent PLC and in $217(5.2 \%)$ it was positive. The

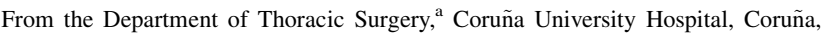
Spain; and Department of Thoracic Surgery, ${ }^{\mathrm{b}}$ Mútua Tarrasa University Hospital and CIBERES Lung Cancer Group, Terrassa, Barcelona, Spain.

Disclosures: Authors have nothing to disclose with regard to commercial support.

Received for publication Sept 27, 2014; accepted for publication Sept 28, 2014; available ahead of print Oct 18, 2014.

Address for reprints: Diego Gonzalez-Rivas, MD, Department of Thoracic Surgery, Coruña University Hospital, Xubias 84, 15006 Coruña, Spain (E-mail: diego. gonzalez.rivas@sergas.es).

J Thorac Cardiovasc Surg 2014;148:2665-6

$0022-5223 / \$ 36.00$

Copyright (c) 2014 by The American Association for Thoracic Surgery

http://dx.doi.org/10.1016/j.jtcvs.2014.09.102
}

analyses of the prognostic impact of PLC confirmed the results of previous studies: a positive PLC was associated with a worse prognosis. In addition, the authors analyzed survival according to a published recommendation to increase the T category of the tumor by 1 if PLC was positive. They found that this increase in $\mathrm{T}$ category was appropriate because they did not find significant differences in survival between the new T categories (tumors with positive PLC) and the same categories with negative PLC. ${ }^{7}$ In the light of their results, the authors elaborated on the fact that the results of PLC should be incorporated into the TNM classification, because the TNM classification assists in making therapeutic decisions. However, there are 3 important issues that should be pointed out.

First, the results of PLC are already incorporated into the TNM classification. As the authors comment, PLC is included in the present coding in the $\mathrm{R}$ (residual tumor) classification, and the R classification is part of the TNM classification, but it is not a $\mathrm{T}, \mathrm{N}$, or $\mathrm{M}$ descriptor. This does not mean that it is less important. The coding for positive PLC is $\mathrm{R} 1 \mathrm{cy}+$ ), indicating that the resection is incomplete by virtue of the positive PLC.

Second, the established rule for any new potential T, N, or $\mathrm{M}$ descriptor is that the new descriptor should be the same for the clinical and the pathologic classifications. In the case of PLC, it is clear that this descriptor is determined exclusively at pathologic staging, but it cannot be determined (at least easily) at clinical staging; it would require a thoracentesis with intrapleural instillation of serum and then retrieval of the fluid or a thoracoscopy during which PLC could be performed. This is the main reason why PLC has not been incorporated as a new descriptor in the T component of the classification: there is no clinical validation for the descriptor.

Third, although the TNM classification helps in making therapeutic decisions and therapy is often guided by tumor stage, therapeutic recommendations should derive from properly designed clinical trials and not from mere taxonomic changes based on survival differences. ${ }^{8,9}$ Therefore, the fact that PLC is not incorporated as an official $\mathrm{T}$ descriptor should not prevent us from advising postoperative adjuvant therapy or designing clinical trials. Adjuvant therapy should be considered, as in any tumor that has been incompletely resected, in patients with full understanding of the surgical results and of the lack of therapeutic trials for this specific condition. So, patients should be aware of the uncertainties of adjuvant therapy in cases of positive PLC. 
The main limitations of this study were that PLC technique was not standardized and the result was obtained after resection. The goal of preoperative staging is to select patients who would benefit from upfront surgery or induction therapy. Some studies conclude that pleural lavage performed at the time of resection will not effectively select patients for induction therapy. The inherent risks associated with thoracotomy are factors that support this conclusion. ${ }^{10}$ However, preoperative PLC, via thoracentesis or minimally invasive techniques, would avoid the risk of thoracotomy and its results could be used to make further therapeutic decisions. The results of this study add to the growing evidence of the value of PLC, emphasize the importance of keeping it in the TNM classification, and improve our capacity to refine the prognosis for an individual patient. Therefore, it should be performed in all lung cancer resections with radical intent.

\section{References}

1. Sobin L, Gospodarowocz M, Wittekind C, eds. TNM Classification of Malignant Tumours. 7th ed. Oxford: Wiley-Blackwell; 2009:138-46.
2. Edge SB, Byrd DR, Compton CC, Fritz AG, Greene FL, Trotti A III, eds. Cancer Staging Manual. 7th ed. New York: Springer; 2010:253-70.

3. Goldstraw P, ed. Staging Manual in Thoracic Oncology. Orange Park, Fla: Editorial Rx Press; 2009.

4. Lim E, Ali A, Theodorou P, Nicholson AG, Ladas G, Goldstraw P. Intraoperative pleural lavage cytology is an independent prognostic indicator for staging nonsmall cell lung cancer. J Thorac Cardiovasc Surg. 2004;127:1113-8.

5. Boylan AM, Wang XF, Ko R, Watson PM, Gu L, Harpole D, et al. Detection of human telomerase reverse transcriptase mRNA in cells obtained by lavage of the pleura is not associated with worse outcome in patients with stage I/II non-small cell lung cancer: results from Cancer and Leukemia Group B 159902. J Thorac Cardiovasc Surg. 2013;146:206-11.

6. Lim E, Clough R, Goldstraw P, Edmonds L, Aokage K, Yoshida J, et al. Impact of positive pleural lavage cytology on survival in patients having lung resection for non-small-cell lung cancer: an international individual patient data meta-analysis. J Thorac Cardiovasc Surg. 2010;139:1441-6.

7. Kameyama K, Okumura N, Miyaoka E, Asamura H, Yoshino I, Tada H, et al. Prognostic value of intraoperative pleural lavage cytology for non-small cell lung cancer: the influence of positive pleural lavage cytology results on $\mathrm{T}$ classification. J Thorac Cardiovasc Surg. 2014;148:2659-64.

8. Boffa D, Detterbeck F, Smith EJ, Rami-Porta R, Crowley J, Zelterman D, et al. Should the 7th edition of the lung cancer stage classification system change treatment algorithms in non-small cell lung cancer? J Thorac Oncol. 2010;5:1779-83.

9. Boffa DJ, Greene FL. Reacting to changes in staging designations in the 7th edition of the AJCC staging manual. Ann Surg Oncol. 2011;18:1-3.

10. D'Amico TA. Value of intraoperative pleural lavage in staging non-small cell lung cancer. J Thorac Cardiovasc Surg. 2004;127:947-8. 